\title{
Minimally invasive palliative resection of lumbar epidural metastasis
}

\author{
Andrew Yew, M.D., Jon Kimball M.S., Patrick Pezeshikian M.D., and Daniel C. Lu, \\ M.D., Ph.D.
}

Department of Neurosurgery, Ronald Reagan Medical Center, University of California Los Angeles, Los Angeles, California

\begin{abstract}
Spinal metastatic lesions are the most common tumors encountered by spinal surgeons. As with procedures for degenerative disease, minimally invsive surgery techniques have been applied to minimize muscle and soft tissue destruction in procedures for tumor resection. Here, we present a 23-year-old female with radiculopathy and foot drop secondary to nerve root compression by epidural metastases from Ewing's sarcoma.

This patient had a history of previous resection and instrumentation as well as multiple rounds of chemotherapy and radiation that failed to control her disease. The patient presented with three weeks of radicular pain and foot drop that was continuing to worsen at the time of her operation. The decision was therefore made to perform a palliative resection and decompression for relief of her progressive symptoms. In this video, we demonstrate a palliative tumor debulking and nerve root decompression utilizing an MIS approach.

The video can be found here: http://youtu.be/tq4kbvKTebI.

(http://thejns.org/doi/abs/10.3171/2013.V2.FOCUS13225)

KEY WoRDS • epidural metastasis $\bullet$ lumbar $\bullet$ palliative resection
minimally invasive $\bullet \quad$ video
\end{abstract}

Manuscript submitted May 14, 2013.

Accepted May 30, 2013.

Please include this information when citing this paper: DOI: 10.3171/2013.V2.FOCUS13225.

Address correspondence to: Daniel C.Lu,M.D.,Ph.D., Department of Neurosurgery, University of California, Los Angeles, 650 Charles E. Young Drive South, CHS 74-129, Los Angeles, CA 90095. email: dclu@mednet.ucla.edu. 